\title{
Representação Social de Eventos Somáticos Ligados à Esquistossomose ${ }^{1}$
}

\section{Social Representation of Organic Processes Related to Schistosomiasis}

\section{Brani Rozemberg ${ }^{2}$}

ROZEMBERG, B. Social Representation of Organic Process Related to Schistosomiasis. Cad. Saúde Públ., Rio de Janeiro, 10 (1): 30-46, Jan/Mar, 1994.

The aim of this research is the critical analysis of the social representation of schistosomiasis in an endemic area in the State of Espirito Santo, Brazil. The results are presented in three papers in order to allow for an in-depth explanation of the interrelationship and conditionings related to the ways in which the population perceive schistosomiasis. This paper approaches the representation of schistosomiasis as an organic process, including the following topics: symptoms, etiology, and treatment.

By transposing an assessment of "level of knowledge", we found that "knowledge" alone does not have the minimum necessary elements to warrant logical consistence from the point of view of the population. The practical measures of control programs carried out by the National Health Foundation strongly influence social representation of the disease.

The creation of a myth concerning snails - as elements capable of entering the human body and eating away at one's insides - exerts an overwhelming influence over the population. We discuss the population's limited belief in the existence of such a disease, and the role played by the medicine prescribed in the area. The "snail myth" diverts attention from the discussion of sanitary measures and general living conditions related to schistosomiasis.

Key words: Social Representation; Schistosomiasis; Health Education.

\section{INTRODUÇÃO}

Os dados aqui apresentados integram o estudo acerca da "Representação Social da Esquistossomose em Área Endêmica", proposto inicialmente com a finalidade de subsidiar a elaboração e a contextualização de uma mensagem de vídeo educativo sobre o tema. No entanto, a pesquisa realizada terminou por originar uma série de reflexões abrangentes, ligadas à representação popular da etiologia, sintomatologia, transmissão, tratamento e prevenção desta endemia, permitindo conhecer algumas das repercussões dos conteúdos e práticas normal-

${ }^{1}$ Pesquisa Financiada pelo Programa de Bolsas do SER/IDR/UNDP/World Bank/WHO

${ }^{2}$ Departamento de Ciências Biológicas da Escola

Nacional de Saude Pública. Rua Leopoldo Bulhões 1 480, Rio de Janeiro, RJ, 21 041-210, Brasil. mente empregados nas campanhas de controle da esquistossomose entre moradores de uma área endêmica.

A análise do material bruto das entrevistas então realizadas nos surgiu uma subdivisão das temáticas ligadas à esquistossomose segundo dois eixos principais: 1. representações de eventos somáticos da esquistossomose e ações humanas frente a eles; e 2. representações relacionadas ao meio ambiente, eventos ecológicos e ações humanas frente a eles. O primeiro eixo temático, objeto deste artigo, inclui os tópicos sintomatologia, etiologia e tratamento, enquanto um segundo artigo ocupa-se das questões relacionadas com o ciclo de transmissão e com a prevenção da endemia. Finalmente, um terceiro artigo apresentará a hipótese resultante desta pesquisa, que subsidiou a construção da mensagem do vídeo produzido e os resultados da avaliação deste material. 
O desmembramento da temática ligada à representação da esquistossomose através dos eixos corpo $\mathrm{x}$ ambiente, para fins didáticos de apresentação dos resultados, foi a opção que menos comprometia a integridade dos discursos dos sujeitos, permitindo, ao mesmo tempo, que se abrisse espaço para uma discussão mais pormenorizada sobre a ampla gama de questões suscitadas em cada tópico, bem como sobre suas implicações e inter-relações.

No presente artigo, para trabalharmos as representações de eventos somáticos ligados à esquistossomose, tivemos como pressuposto uma das conclusões fundamentais do trabalho de Pinto (1981). Segundo este autor, ainda que o raciocínio concreto (que caracteriza o grupo de agricultores por nós entrevistados) não se utilize a formalização característica do pensamento dos adultos que receberam formação tradicional, ele não se torna menos real ou menos válido para a ação. É necessário descobrir, sob a forma aparentemente não-lógica do pensamento concreto, as proposições universais não-verbalizadas que se encontram implícitas para podermos captar toda a riqueza do raciocínio e sua validade prática e existencial.

Certamente, o presente estudo não esgota a riqueza da experiência concreta, dos questionamentos e das representações partilhadas pelos moradores da área endêmica investigada acerca da esquistossomose. Entretanto, ele aponta um conjunto de percepções mistificadas e ideologizadas que parecem resultar de padrões culturais tradicionais e de ações educativas com estas mesmas características. Contudo, o maior interesse deste trabalho advém dos esforços por parte da população no sentido de compreender as informações sobre esquistossomose difundidas na região. Esta busca de ocorrência e de sentido no universo em que vivemos, característica do pensamento humano, nem sempre é levada em conta pelos profissionais de saúde, sobretudo quando trabalham com grupos nãoalfabetizados, cuja capacidade de pensar logicamente é muitas vezes subestimada. Ao apresentarmos aqui os sinceros esforços dos moradores de uma área endêmica no sentido de compreender o discurso do saber médico, esperamos motivar os mesmos sinceros esforços por parte do saber médico no sentido de compreender e respeitar os discursos construídos em outras sintaxes culturais.

\section{O PROCESSO DE INVESTIGAÇÃO}

O trabalho foi desenvolvido numa área rural endêmica do município de Conceição do Castelo, na região serrana do estado do Espírito Santo, Brasil. Colonizado por imigrantes italianos e portugueses no início do século, o município subsiste basicamente da produção de café e, em menor escala, da criação de gado. A área compreende 25 localidades contíguas (cerca de 2.500 habitantes e um total de 579 residências), tendo sido a mesma escolhida por apresentar índices em torno de $30 \%$ de prevalência de esquistossomose, segundo dados da Superintendência de Campanhas da Fundação Nacional de Saúde (Sucam/FNS, 1991).

Para a contextualização do estudo das representações sobre a doença, levantamos dados de perfil sócio-econômico e realizamos um inquérito de morbidade referida (IMR) utilizando um instrumento de pesquisa composto por questões abertas e de múltipla escolha. O objetivo da aplicação do IMR foi a sondagem do nível de referências espontâneas à esquistossomose, sem qualquer menção, por parte do pesquisador, ao seu interesse específico nesta doença, de modo a dimensionar a importância atribuída ao problema na área em estudo.

Para aplicação do referido instrumento de pesquisa foi adotado o procedimento de amostragem sistemática, considerando-se para o cálculo do tamanho da amostra apenas a população adulta, estimada em 1.500 indivíduos. O limite de erro de estimação foi fixado em $10 \%$. A amostra obtida foi de 93 indivíduos, o que, no conjunto das 579 residências, corresponde a um intervalo amostral de 6 residências. Assim, a cada 6 residências entrevistamos um adulto, alternadamente homem/mulher, perfazendo, ao final, 92 entrevistados. Para nossa orientação no campo utilizamos croquis das 25 localidades, fornecidos pela Sucam/FNS.

Para o estudo da representação social da esquistossomose, onde privilegiamos a profundidade e a literalidade dos depoimentos dos sujeitos, trabalhamos com apenas dois terços da 
amostra de 93 entrevistados, ou seja, 62 indivíduos, o que fez com que, para fins de análises quantitativas, o coeficiente de variação dos resultados aqui obtidos passasse a ser de $12 \%$. Para esta etapa, aproveitando o mesmo sistema de amostragem já descrito, a cada três casas da amostra anterior a primeira era sistematicamente excluída, sendo que nas outras duas realizávamos, além do questionário já referido, uma segunda etapa de entrevista, de acordo com um roteiro semi-estruturado que contemplava a questão da esquistossomose através dos seguintes temas: Sintomatologia, Diagnóstico e Tratamento, Etiologia, Transmissão e Prevenção.
Um roteiro de questões foi sendo aprimorado durante a fase de pré-testes no campo (Quadro 1). Este roteiro foi utilizado a fim de que todos os temas fossem contemplados pelos entrevistados, porém sem rigidez quanto à ordem de abordagem. Das 62 entrevistas resultantes desta etapa, 23 foram registradas apenas por escrito e 39 foram gravadas em fitas $\mathrm{k}-7$, devido ao fato de, nestas últimas, os entrevistados terem discorrido mais longamente sobre as experiências vividas ou devido a desdobramentos das questões propostas. A receptividade à participação na pesquisa foi de $100 \%$ e as 62 entrevistas, que incluíam as duas etapas, tiveram, em média, uma hora e meia de duração.

QUADRO 1. Roteiro Semi-Estruturado para Análise da Apresentação Social da Esquistossomose.

Sintomatologia e Representação de Fatos Somáticos

1. Você já teve a doença do caramujo?

2. O que sente a pessoa quando está com esse problema?

3. O que mais pode acontecer com quem está com a doença do caramujo? Por quê?

4. Que parte do corpo é atingida?

5. Como soube disso? (No caso de respostas às questões anteriores)

Diagnósticos e Tratamento

6. Como descobriu que estava com a doença? (No caso de entrevistados que já tiveram a doença)

7. Como é que se trata este problema?

8. E o tratamento resolve o problema? (Em relação ao tratamento referido)

Epidemiologia

9. Quanta gente tem essa doença na região?

10. Por que motivo umas pessoas têm e outros não?

Etiologia

11. O que é a doença do caramujo?

12. Você já viu o caramujo?

Transmissão

13. Como se pega a doença do caramujo?

14. Como o verme entra/sai do corpo?

Participação das Feses na Transmissão

15. Já ouviu falar nas fossas higiênicas?

16. Qual a importância disso? O que tem isso a ver com a doença do caramujo?

Prevenção

17. O que pode ser feito para evitar esse problema? 


\section{Métodos de Análise de Dados}

Os dados de perfil sócio-econômico e de morbidade referida foram tabulados e analisados, sendo incluída neste artigo apenas uma síntese destes resultados, de modo a contextualizar as análises aqui realizadas.

Os depoimentos sobre a esquistossomose foram transcritos na íntegra em dois fichários, a fim de facilitar a análise do material bruto, e trabalhamos separadamente segundo a mesma metodologia, através dos eixos temáticos referidos na introdução. Dentre as questões indicadas no roteiro de entrevistas, serão analisadas aqui somente aquelas referentes à sintomatologia, etiologia e tratamento, uma vez que estas compõem o primeiro eixo temático, objeto deste artigo.

Nas análises realizadas, foram as leituras dos depoimentos que sugeriram a rede de questões (temas e subtemas) segundo as quais os dados foram sendo agrupados e interpretados. Assim, por exemplo, a leitura de um determinado depoimento sugeria um subtema relevante, que era reencontrado na leitura de outros depoimentos. Desta maneira, foi possível, ainda, procedermos à quantificação de alguns dos aspectos levantados por esta pesquisa.

Nossos dados passaram pelo processo de análise descrito por Minayo (1992), que inclui etapas de categorização sucessivas, descrição (totalidade dissociada em partes), contextualização, bem como compreensão e explicação das inter-relações e condicionamentos associados ao modo como os indivíduos conferem e atribuem sentido à esquistossomose a partir de sua vivência na área endêmica.

\section{RESULTADOS}

\section{Características da População}

Dentre os entrevistados, $89,2 \%$ nasceram no próprio município de Conceição do Castelo ou nos municípios limítrofes. As mudanças de residência são raras e restritas aos municípios vizinhos, destacando-se que $44,1 \%$ jamais se mudaram do município onde nasceram.

Segundo a ocupação, 95,6\% dos homens entrevistados são lavrados; entre as mulheres,
$97,8 \%$ são donas de casa, sendo que $36 \%$ delas definem-se como sendo também lavradoras. Quanto à escolaridade, 36,5\% nunca estudaram, $22,6 \%$ cursaram as primeiras séries primárias (destes, menos de um terço diz saber ler e escrever), 30,4\% concluíram o curso primário, $7,0 \%$ freqüentaram alguma série do curso ginasial, e apenas 3,5\% cursaram o secundário.

Ainda entre os entrevistados, 47,3\% são proprietários da terra que cultivam, $47,3 \%$ são colonos e 5,4\% são assalariados. O sistema de relações de trabalho é o mesmo desde o início do século: os colonos entregam metade da sua produção cafeeira aos proprietários das terras que cultivam. Além disso, 45,5\% deles fornecem a terça parte da sua produção de arroz, $36,4 \%$ da sua produção de milho e $36,4 \%$ da sua produção de feijão, sendo que este procedimento vem se tornando cada vez mais raro, já que os preços elevados dos insumos agrícolas e o baixo preço pago por tais produtos tornam sua produção insuficiente, até mesmo para a subsistência das famílias dos colonos. Dentre os proprietários de terra, 81,8\% dependem, assim como os colonos, exclusivamente da força familiar na lavoura.

As atividades sociais raras, destacando-se os encontros promovidos pela Igreja Católica, referidos por $86 \%$ dos entrevistados. A freqüência a estes e outros eventos sociais é limitada pelo excesso de trabalho e pelo cansaço decorrente do mesmo. Outro fator limitante, neste aspecto, é a ausência de transportes coletivos, aliada as longas distâncias a serem percorridas em estradas de barro. Dentre os entrevistados, $59,2 \%$ não possuem veículos automotores e, dentre estes, 23,6\% também não possuem bicicletas ou animais de montaria, não dispondo, portanto, de qualquer meio de transporte.

Dentre as atividades econômicas relacionadas com a transmissão da esquistossomose destaca-se o plantio de arroz em terrenos alagados, referido por $35,5 \%$ dos entrevistados sobre esquistossomose como sendo uma das formas de se contrair a doença.

\section{O Inquérito de Morbidade Referida e a Experiência com a Esquistossomose}

$\mathrm{Na}$ Tabela 1, os problemas levantados no Inquérito de Morbidade Referida foram listados 
por ordem de freqüência, sendo que o mais freqüente dentre eles foi estudado à parte (Rozemberg, s/d).

As verminoses foram o quarto problema mais aludido (Tabela 1), sendo que a maior parte não foi especificada e apenas três referências corresponderam especificamente à esquistossomose, conhecida na região como "caramujo" ou "doença do caramujo". Chama a atenção, ainda, o alto nível de referências a dores de barriga, o quinto problema mais aludido, que figuram aqui como categoria independente de agravo à saúde, apesar de terem sido o segundo sintoma mais freqüentemente atribuído à doença do caramujo (ver Tabela 2).

Quanto ao tempo de duração dos problemas referidos é importante observar que, apesar de a questão proposta dizer respeito aos problemas de saúde vividos nas últimas 48 horas, foram descritos, em sua maioria, problemas com mais de 1 ano de duração $(64,5 \%)$. Chama a atenção a alta frequiência de problemas vivenciados há mais de 10 anos (24,5\%), revelando a importância atribuída aos problemas crônicos antigos na representação social da doença.

Em relação à questão "Você já teve a doença do caramujo?", dentre as 62 pessoas entrevistadas, $74,2 \%$ responderam afirmativamente. Outros $25,8 \%$ disseram nunca ter tido a doença porém $20,9 \%$ dentre estes informaram que seus filhos ou cônjuges já tiveram ou estão com a doença. Portanto, apenas 4,8\% nunca experimentaram a doença em si mesmos e/ou em familiares moradores, e apenas um dos entrevistados $(1,6 \%)$ nunca ouviu falar deste problema. Em resposta a esta questão, foram freqüentes as referências espontâneas à Sucam, órgão governamental, que entre outras ações, realiza o diagnóstico e o tratamento da doença em áreas endêmicas. Presença já familiar aos moradores, o guarda da Sucam foi, para muitos, o primeiro a introduzir informações sobre a existência deste problema: "a primeira vez que ouvi falar nisso foi a Sucam procurando caramujo". Dos entrevistados, $42 \%$ acrescentaram à sua resposta o último resultado da Sucam sobre sua família: "a última vinda da Sucam acusou caramujo em mim e nos dois garotos"; "a última vez deu em todos da família". Revelando-se um importante mediador entre o saber médico e a experiência da população com o problema do caramujo, o trabalho de monitoração regular da Sucam tornou possível, ainda, que $47 \%$ dos entrevistados acrescentaram espontaneamente às suas respostas o número de vezes que tiveram a doença: $21 \%$ a tiveram uma vez; $13 \%$, duas vezes; $6,5 \%$, três vezes; $3,2 \%$, quatro vezes; e $3,2 \%$ cinco vezes. Em alguns casos foi expressa a perplexidade frente à quantidade de vezes em que se viveu o problema em um curto espaço de tempo: "só no ano passado eu tomei remédio de caramujo quatro vezes no ano!”.

Em relação à questão "Quanta gente tem caramujo na região?", $87,5 \%$ das respostas incluíram expressões do tipo "muita gente", "a maioria das pessoas", "em todas as casas sempre tem alguém com esse verme". Os demais $12,5 \%$ preferiram não generalizar, limitando-se a tentar situar os locais e residências aonde "deu caramujo" nos últimos exames.

\section{Sintomatologia}

Em resposta à questão "O que sente quando está com a doença do caramujo?", dos 62 entrevistados, 22,5\% disseram que eles próprios ou seus familiares não sentem absolutamente nada:

J.F. - "Eu tenho bastantes problemas de saúde, não dá pra ficar sem remédio. Agora, pelo caramujo eu nunca senti nada não."

L.G.L. - "Não sentia nada. Só soube por causa do exame da Sucam, que acusou caramujo. Aqui em casa uma porção de filhos deu, mas nenhum reclamava de nada não."

Os $77,4 \%$ restantes associam uma série de sintomas e sinais ao resultado positivo do exame de fezes. Tais sintomas encontram-se dispostos na Tabela 2, por ordem de frequiência, e dizem respeito às experiências pessoais e familiares dos entrevistados com a doença do caramujo, destacando-se a fraqueza como sintoma mais freqüentemente referido. A fraqueza é aferida pelo modo como interfere no desempenho e na produtividade frente às tarefas materiais concretas que caracterizam a rotina diária desta população: 
TABELA 1. Freqüência dos Problemas de Saúde Vividos na Família nas 48 horas anteriores à Entrevistas $(\mathrm{n}=93)$

Problemas de Saúde Referidos

Problema de Nervos, 21; esgotamento nervoso, 3; disritmia, 1; com perda de consciência, 4; ansiedade, 2; em doentes mentais, 2.

Problema de Gripe, 7; com tosse, 16; com dor de garganta e dor de cabeça, 2; com dor no peito, 1; com febre, 2; com enjôo, 1.

Problema de Pressão, 8; hipertensão arterial, 1; pressão baixa, 1; pressão alta, 13; dor de cabeça e tonteira, 1.

Vermes, 8; com dores nas pernas, 3; necátor, 3; caramujo, 2; esquistossomose, 1; "verme brabo" (strongiloides), 1 .

Dor de Barriga, 4; com tonteira, 2; com vômito, 2; com cólicas, 2; desande, 2; com dor nas pernas, 2.

Problema de Estômago, 3; fraqueza no, 2; coisa ruim no, 1; gastrite, 6; queimação por dentro do estômago, 1 .

Problema de Coluna, dores na; 4; com dor nas cadeiras, 2; bico-de-papagaio, 1; com febre e dor de cabeça, 1; com dor nas costelas, 2; hérnia de disco, 1.

Reumatismo, 3; reumatismo no sangue, 5; com dor nas juntas, 1; com dor nos braços, 1; reumatismo na mão, 1 .

Problemas nas Vistas, 2; vista curta, 2; vista escura, 1; enxerga pouco, 1; catarata, 1; pressão alta na vista, 1 ; vista inflamada, 1 ; devido aos vermes, 1 .

(Problemas do Aparelho Urinário): problemas de rim, 3; dor nos rins, 1; urina presa, 2;

bexiga arriada, 2; pedra na bexiga, 2; infecção urinária, 1; sangue na urina, 1 .

Anemia, 4; anemia com fraqueza, 1; anemia no sangue, 3.

Coração, 6; "valva mitral", 1 .

Sinusite, 3; sinusite alérgica, 1; com falta de apetite, 1 ; de pneumonia mal curada, 1.

(Acidentes): tombo, 1; furou o pé, 1; torceu o tornozelo, 1; acidente de trabalho, 1; acidente de automóvel, 1.

Dor de Cabeça, 2; que nunca passa, 3.

Varizes

Nascida (furúnculos)

Bronquite, 2; agravada pelo frio, 1.

Dentes por Arrancar, 2; devido à inflamação, 1.

Hemorróidas, 1; "morróides", 1; "morodes", 1.

Fígado, 2; cólicas de, 1.

Inflamação de Ovário, 1; com corrimento, 1.

Garganta, com amígdalas crescidas, 1; que dá febre e incha, 1.

Asma

Tireóide

Alergia

Derrames (seqüelas)

Dormência nas Mãos

Esipra (erisipela) 1; que nunca sara, 1.

Hérnia

Verme Giárdia

Coceira, 1; insuportável, 1.

Foram referidos uma única vez os seguintes problemas de saúde:

diabetes; colesterol; berne; pulmão; fala presa; bursite; perda de memória; sangramento do nariz; dor nas pernas; dor no corpo todo; períneo por operar, febre paratife; problema do gato (toxoplasmose); mosquito afetado (leishmaniose); doença de Chagas; picada de barbeiro; gravidez problemática.

Obs.: Foram listadas as diferentes maneiras pelas quais os problemas foram referidos. Incluímos sintomas quando estes faziam parte da denominação do problema pelos entrevistados. As informações entre parênteses são nossas, extraídas de dados das descrições dos problemas ou de exames médicos que nos foram apresentados pelos entrevistados. 
J. S. - "A minha filha sentia muito desânimo. A gente mandava ela trabalhar, fazer alguma coisa, ela não tinha vontade de fazer nada, trabalhar assim, lavar umas vasilhas, tratar uma criação. Assim, não tinha animação. Então, quando deu nela, eu logo conheci, né?" A.B. - "Na roça, quando a gente abaixa, pegou um peso e colocou nas costas, já cai no chão, não güenta carregar aquilo não. Aí começa a tonteira, as vista fica todo bambo. É sempre assim o problema do caramujo, não tem jeito. $E$ todo ano a gente tem ele. Vem com dor de cabeça, vista escura. Só vê aqueles grilinhos voando na frente dos olhos, assim."

Em relação às questões "O que mais pode acontecer com quem está com a doença do caramujo?" e "Que parte do corpo é atingida?", obteve-se um nível elevado de referências à experiência com episódios graves entre parentes e conhecidos $(32,3 \%)$, dado não esperado numa área de média endemicidade. Somando-se a estes os entrevistados que reproduziram narrativas de terceiros sobre as formas graves da doença, encontramos que $58,1 \%$ da amostra estão a par das possíveis decorrências graves da doença.

Ainda em relação aos sintomas, verificamos que eles têm forte influência nas representações da ação do caramujo no interior do corpo:

A.B. - "Em mim o caramujo deu nos nervos. Eu sentia assim uma piscadeira no olho, demais, quase não parava! Piscava de fazer medo. Ficava assim diária, né. Então o médico falou que podia ser caramujo. Fez exame e deu. Os caramujo me atacava nos nervos."

Assim como a localização dos sintomas, o tipo de exame diagnóstico realizado também influencia a representação do local do corpo afetado pelo caramujo. Deste modo, uma vez detectada através de exame de sangue, a doença é entendida como adstrita ao sangue. É o que se verifica também para as categorias referidas na Tabela 1 como "anemia no sangue" e "reumatismo no sangue".

Dentre todas as decorrências graves atribuídas à doença, a que causa maior impacto no imaginário local é a barriga-d'água. As demais decorrência, mesmo quando graves, não são percebidas de forma tão flagrante quanto o crescimento desproporcional da barriga, que todas as vezes que foi descrito teve a morte como conseqüência:

G.L.G. - "Sei que eles foram tirando a água da barriga dela. Quanto mais tirava, mais aumentava. A última vez tiraram 16 litros d'água! Depois ela morreu num estado muito triste."

A permanência do caramujo por muito tempo no organismo é referência constante nas narrativas de casos graves. $\mathrm{O}$ desenvolvimento de tais quadros é em geral atribuído ao não-reconhecimento do problema a tempo de curar ou ao fato de, uma vez reconhecido a tempo, o problema não ser tratado, deixando-se que atinja um estado "muito afetado", responsável pelas mortes e por danos irreversíveis à saúde:

A.B. - "Morreu uma mulher aqui de barriga d'água. A pessoa fica com aquela barriga e o caramujo vai comendo o sangue, chupando o sangue todinho, até que o sangue da gente se transforma em água. Depois, se o camarada deixar o caramujo na barriga 10 anos, quando faz o exame o sangue já está em água. Aí não tem jeito mais. Dá anemia passada e acabou, nunca mais."

A inexistência de recursos diagnósticos e terapêuticos disponíveis é apontada como fator fundamental nestes relatos, que têm em comum ainda o fato de enfatizarem tal situação como mais freqüente no passado, numa época em que as pessoas, sem a monitoração regular do problema, eram surpreendidas pela doença já em estado avançado. Os dados revelam, entretanto, que o desconhecimento das possíveis decorrências graves do caramujo não é uma situação totalmente pertencente ao passado. $\mathrm{O}$ material de pesquisa nos permite configurar um processo dinâmico de transição entre o desconhecimento e o acesso às informações, ainda que truncadas, decorrentes da observação das práticas médicosanitárias, das derivações das mesmas no imaginário local e da ampla gama de recomendações preventivas divulgadas na área:

S.A. - "Ouvi dizer que através do caramujo pode transmitir câncer na pessoa. Eu só fui saber que era perigoso há muito pouco tempo. De primeiro a gente vê falar nisso e não se importa." 
TABELA 2. Freqüência dos Sintomas atribuídos à Doença do Caramujo $(n=62)$

\begin{tabular}{ll}
\hline \hline Sintomas & \\
Fraqueza, 15; não agüenta trabalhar, carregar peso, 4; não agüenta andar, & 31 \\
1; sair de casa, 2; subir o morro, 2; desânimo, 5; cansaço, 2. & 17 \\
Dor de barriga, 12; todo dia, 1; seca, 1; quando os vermes andam, 2. & 12 \\
Dor de estômago & 11 \\
Dor de cabeça & 11 \\
Zonzeira, tonteira & 10 \\
Dor nas pernas & 6 \\
Enjôo, nojo, vômito & 5 \\
Não aceita comer & 4 \\
Come demais & 4 \\
Incha a barriga & 3 \\
Sono, soneira & 2 \\
Vomitar sangue & 2 \\
Evacuar sangue & 4 \\
Dor do lado, 2; que era baço, 1; que era fígado, 1 & 3 \\
Palidez, 1; rosto amarelo, 1; pele manchada, 1 & 3 \\
Dor no corpo, dor por dentro do corpo & 2 \\
Anemia & 2 \\
Suor frio & 2 \\
Vista escura & \\
\hline
\end{tabular}

Os seguintes sintomas foram referidos uma única vez:

tremores; insônia; dor nas cadeiras; mal-estar; aumento da pressão; piscadeira no olho; emagrecimento; azia, perfurou meu rim; tive que tirar o baço; operei caramujo.

P.B. - "Esses dias teve uma palestra aí e eles falaram que vira coisa grave, né? Acaba a pessoa morrendo daquilo (...) Eu achava que nem era tão... , né? Pensava: Ah! Coisinha à toa. Mas agora eu penso: o verme é coisa grave mesmo, porque se não tratar dele, ele vira outra coisa!"

\section{Etiologia}

Através das questões "O que é o caramujo?" e "Você já viu o caramujo?", procuramos trabalhar melhor o que efetivamente seria "caramujo" para a população. Tais questões foram propositalmente formuladas sem que especificassemos se nos referíamos ao caramujo "doença" (e/ou agente etiológico) ou ao caramujo "animal" (molusco transmissor). Isto porque o nosso interesse foi justamente checar em que medida tais distinções existiam para o grupo e observar como as relações entre estes elementos seriam espontaneamentes representadas. Apresentando uma síntese relativa à frequiência de distinção entre agentes etiológico e molusco transmissor nas respostas de 62 entrevistados à questão "O que é Caramujo" temos as seguintes categorias: a) $17,7 \%$ não conhecem (mas $6,8 \%$ já ouviram falar que existe); b) $37,3 \%$ fizeram distinção entre o agente etiológico e o molusco transmissor; c) $46,7 \%$ sugerem ou afirmam que o molusco é o próprio agente etiológico (que penetra o organismo humano).

$\mathrm{Na}$ categoria $\mathrm{C}$ que corresponde à maior parte dos entrevistados $(47,5 \%)$, a idéia apresentada é a de que o molusco é ele próprio o agente externo que, uma vez alojado no organismo humano, provocaria a doença. Para estes mesmos entrevistados, no entanto, tal idéia, que, segundo eles, é veiculada pelo saber médico, parece absurda ou ridícula. A perplexidade gerada pela ausência de consistência lógica desta idéia faz com que, junto com ela, caiam no descrédito outras idéias ligadas à doença também divulgadas pelo saber médico:

A.P. - "Eu já vi o caramujo. Eles [Sucam] mostraram. Porque ali tem um poço de peixe. 
E eles pescaram. Não tem aquele negócio deles pescar? Aí então eles pegaram o caramujo, mas eu não sabia que era aquilo não. Você acha que é? Eu não acreditei não! é um bicho grande assim ó! Ave Maria! Eles pescaram e vieram aqui me mostrar se eu tinha visto, se eu conhecia. Aí eu falei: Não. E ele me mostrou. $E$ foi desse poço de peixe que tem aqui. E meus menino pesca diária aí! Mas sei lá, eu... eu custo até a acreditar. Porque na água, se tiver um bicho grande daquele você vai tomar? Diz que ele entra quando é miudinho. Foi o que o home falou. Depois diz que vai ficando grande. E fica grandão assim! Mas eu não acredito não. Aliás, eu quase não acredito que existe coisa de caramujo assim. Eu fiquei pensando que era esse bicho, e aquilo me colocou emocionada! Eu não acredito não! Porque, como é que pode vir na gente uns bichos daqueles?"

F.V. - "Agora aqueles caracolzinho que dá assim na água, que eles fala que é caramujo, eu tenho prá mim que aquilo não é não (...) Até na caixa d'água costuma vir aqueles bichinho! Mas aquilo não é o que dá no fígado da pessoa. Aquilo não pode ser não, eu desconfio que não, porque uns bicho daquele vai entrar na gente?'(risos) (intervenção da esposa do entrevistado: 'Uai, mas entra! Entra porque quando a gente faz o exame dá!')

A possibilidade de o caramujo ser a doença faz com que a desconfiança se estenda a outros moluscos, como os gastrópodes terrestres de concha cônica, abundantes nos jardins e no solo dos cafezais:

J.L.B. - "Eu falo que o caramujo é aquele negócio que tem uma lesma, né? $O$ caramujo que nós conhece é aquele. Aí eu penso: será que a gente tem isso na barriga? (...) às vezes eu tô capinando, né, aí eu encontro aquilo e falo: será que é esse bicho que tá me comendo por dentro? Porque aquele a gente dá o nome de caramujo, né?'”

Ainda na categoria C, apenas $10,5 \%$ dos entrevistados parecem não ter dúvidas, deixando sua imaginação atuar sobre os estilhaços de informações recebidas do saber médico. Aqui é plenamente assumida a representação de um molusco, tal como é visto no meio exterior, "morando" dentro do organismo humano:

V.S. - "O caramujo, diz que é um verme escondido dentro de uma capinha, escondida ali, do jeito mesmo destes caramujos que a gente vê por aí, às vezes nas pedras, agarrado no lodo por ali. Assim é ele. A gente toma ele na água e ele vai e transforma naquilo, escondido! Precisa saber do remédio especial pra matar ele ali dentro daquela capinha que ele mora. Mesmo assim, a vez toma aquele remédio, mas depois come uma comida que agrada ele, e daí o remédio não resolve." (E como ele sai do corpo?) "Não saia não. Acredito que ele dissolve por ali. Ele morre. Porque a gente não vê ele! E nem também a gente encontra nas fezes aquela capinha dele [concha do molusco]. Então quer dizer que não entendo."

Passamos agora a apresentar os resultados relativos à categoria $\mathrm{B}$, que perfaz $37,3 \%$ da amostra de entrevistados. Para este grupo, o caramujo, ou verme-caramujo, é entendido como algo muito pequeno que habita o interior do caracol. Verifica-se aqui uma distinção aparentemente bem-demarcada entre os termos "caramujo" e "caracol". Na língua portuguesa, ambos designam moluscos. Na região onde trabalhamos, o termo "caramujo", intensamente divulgado pelas campanhas de combate à esquistossomose, passou a ser utilizado para designar a doença e seu possível agente etiológico - o verme-caramujo -, enquanto o termo "caracol" designa o molusco que lhe serve de morada:

S.B.P. - "O verminho mesmo eu não sei expricar não. Agora esses caracolzinho que eles diz que guarda o caramujo dentro.. Ah! Esse eu mostro prá senhora em qualquer lugar por aí."

A.B. - "O rapaz da Sucam mostrou o caracol. Mas o caramujo no aparelho (microscópio) eu nunca vi não. Só vi o caracol. O rapaz catou lá. Nós tavo batendo o arroz e ele foi lá no meio de nós. Aí pegou na peneirinha deles lá e falou: Ó aqui! Esse punhado aqui. Cada caracolzinho desse tem mil caramujinho dentro (...)" 
V.P. - "O cara da Sucam mostrou a gente um tipo de um caracolzinho que fica no fundo da água, que é onde o verme pode se germinar e viver, né? Agora ele mesmo, o caramujo, eu nunca vi não..."

Nesta categoria, portanto, o caracol é descrito como sendo a "morada", "casinha", "casca" ou "abrigo" onde o verme-caramujo "mora", "vive", "gera" ou "se cria". Tal distinção entre o caracol e o verme poderia ser considerada um indício de uma representação aproximada à científica. Ademais, através da designação "verme" atribuída ao agente etiológico, os entrevistados poderiam estar se referindo à representação científica do que seja um verme. Tal interpretação é inclusive comum nas pesquisas que se destinam a avaliar o nível de conhecimento sobre esquistossomose em populações. Neste caso, tal categoria de respostas corresponderia ao "certo", ou seja, ao conhecimento correto sobre a etiologia da doença. Felizmente, a análise qualitativa, apoiada na profundidade dos depoimentos, nos permitiu resgatar uma representação de "verme" bastante peculiar, demonstrando que o uso de um mesmo termo não significa, absolutamente, que se esteja falando de uma mesma coisa., O verme-caramujo aparece para o grupo como uma espécie de miniatura do caracol, possuindo a mesma natureza deste. Assim, nos desdobramentos dos relatos verifica-se que a distinção entre "caracol" e "caramujo" não é completa e que, com freqüência, um se transforma no outro:

J.S. - "Ele é uma espécie de caramujinho, você já deve ter visto uns caramujinhos assim pequeno. $O$ verme é gerado alí! Eles tem uma saída alí. Por alí é que sai os vermezinho, de dentro daquele caramujo (...) os vermes são muito pequenininhos. $E$ então no nosso corpo eles vão crescer e gerar. E diz que se eles fica determinado tempo alí, eles se transforma naquele caracolzinho alí por dentro do seu intestino. Dalí eles vão é produzindo mais! Dalí eles vão gerando outros e mais outros."

\section{Diagnóstico e Tratamento}

Em resposta à questão "Como descobriu que estava com caramujo?", $100 \%$ dos entrevis- tados já fizeram pelo menos uma vez o exame de fezes junto à Sucam. Destes, 16,5\% descobriram o problema em consultas médicas, enquanto $68 \%$ referem a Sucam como sua exclusiva fonte de detecção do problema. Os demais $15,5 \%$, apesar de referirem a confirmação da Sucam, apoiam-se também no conhecimento adquirido dos sintomas, ou seja, dispõem de uma forma endógena de detecção do problema. As respostas deste grupo minoritário demonstram ainda uma maior autonomia em relação ao trabalho dos guardas da Sucam e um papel menos passivo no processo recorrente de exame e tratamento, pois, ao invés de "sendo tratados", eles se percebem "utilizando" os serviços da Sucam: "Faço os exames mesmo que a Sucam não passe"; "mesmo que a Sucam não venha eu vou atrás de exame de caramujo de 6 em 6 meses".

Em relação à questão, "Como se trata o problema do caramujo?", todos os entrevistados, satisfeitos ou não com os resultados do Mansil (Oxaminiquine), atribuem a ele o status de única droga capaz de combater a doença, não tendo sido referido nenhum outro procedimento ou remédio, caseiro ou industrializado, para combater esta verminose, ao contrário de outras verminoses e problemas apresentados na Tabela 1, para os quais existem inúmeras receitas. "Esse remédio é o que mata eles, né... é o remédio especial prá caramujo. Remédio mais forte que eles, descamba com eles". "Para outros vermes a gente pode usar hortelã, chifre queimado (...) mas para o caramujo precisa ser o remédio especial prá matar ele".

Em resposta à questão "E o tratamento resolve?", $71 \%$ dos entrevistados informam que o tratamento "costuma resolver", "deve resolver", ou "melhora", sendo em geral referido o fim ou o alívio dos sintomas como referencial de resolução do problema. Contudo, este dado quantitativo é pouco elucidativo. Ao longo dos depoimentos, uma série de outros aspectos foram levantados pelos entrevistados em relação ao uso da droga prescrita.

Dos entrevistados, 7,5\% referem a ineficácia do remédio frente ao quadro de reinfecções recorrentes, enquanto para outros $15 \%$ o fato de terem que tomar repetidas vezes o remédio gerou uma representação desta doença como sendo incurável. Neste último caso, o remédio 
passa a ser visto como tendo um poder limitado no controle da doença, sendo que, ao invés de atribuído à recorrência da infecção, o fato é imputado a uma espécie de indestrutibilidade do verme-caramujo dentro do organismo humano:

J.C.L. - "Quem toma uma vez o remédio de caramujo, tem que tomar sempre (...) Porque geralmente quem teve, acusa de novo! Então quer dizer que o remédio sara, mas deixa sempre uma resmazinha do bicho. Alguma coisa sempre fica."

A.G.- "Por aqui tem muita gente que toma o remédio hoje, e inhantes de completar um mês já corre prá fazer exame de novo. Não tá certo! Teria de deixar passar de três mês prá cima. Porque aí já deu o tempo do verme germinar. Ele já evêm germinando de novo no organismo da gente. O remédio não resolve tudo, porque os verme já fica sendo parte do corpo da pessoa. Quando a gente se enfraquece, eles produz mais (...)"

Do total de entrevistados, $8 \%$ referiram a necessidade de se evitar a ingestão de álcool, psicotrópicos e alimentos gordurosos por ocasião do tratamento; $15,1 \%$ relataram terem sofrido intoxicação com o uso do Mansil; e $14,9 \%$ informaram que seus familiares ou conhecidos sofreram intoxicação com o uso desta droga.

Quanto aos relatos acerca da intoxicação de terceiros, em geral estes eram confrontados com a experiência favorável dos próprios informantes por ocasião do uso do Mansil, imputando-se a responsabilidade pela intoxicação à vítima, ou seja, bastaria o usuário seguir as recomendações médicas e "fazer do jeito que o médico manda" que o Mansil não traria maiores problemas. Todavia, a situação é vista de forma bem diferente por aqueles que narram as suas próprias experiências de intoxicação:

M.A.B.P.- "E eu sei que me disseram que peguei na água esse negócio de caramujo. Eu não sentia nada. Mas depois que tomei o remédio comecei sentir tonteiras, vontade de vomitar. Foi do remédio."

Nestes casos, a experiência negativa com o uso do medicamento, unida à insignificância ou mesmo à ausência dos sintomas anteriores ao tratamento, pode concorrer para a veemente rejeição da droga, que foi expressa por apenas um dos entrevistados:

M.R. - “(..) E o home da Sucam me perguntou quando era que a menstruação ia acabar (...) Aí acabou num dia, no outro ele veio e me deu o remédio. Ah, foi só tomar que aquilo começou me tontear. Ah, mas eu vomitava! Não via ninguém! (...) Aquilo rodava a casa toda. Até tarde eu fiquei assim, custou a passar (...) Depois disso, toda vez que a minha menstruação vem me faz tudo aquilo de novo. E foi esse remédio de caramujo que me fez ficar assim. Agora não tomo nunca mais aquilo.” [E se não tomar, o que acontece?] "Esse meu menino, ele também teve problema de... Deu caramujo. Ele começava com dor nas pernas e uma coisa e outra. Daí eles falaro que era do caramujo. Mas não tinha. Não é dizer que ficou ruim não. Aquilo não era nem tanto por causa do caramujo nada!"

O depoimento acima reflete uma postura singular. Para outros entrevistados que referem problemas decorrentes do uso do Mansil, o que se verifica é um quadro de conflito, onde se é obrigado a optar entre duas situações consideradas igualmente desfavoráveis - a doença ou o remédio:

A.B.- "Já tive caramujo três vez. Tomei o remédio. Da primeira vez não valeu de nada, aí peguei tomei de novo. Agora ontem eu tive de tomar a terceira vez... Mas diz o Dr. que o homem que toma remédio de caramujo mais que três, quatro vez, diz que nunca mais ele é homem na vida. Diz que acabou. Porque aí já parte prás doença ruim. Mas tem que tomar, se ficar com ele (caramujo) é pior (...) Fazer o quê? Acontecer o que acontecer, os problema da roça ninguém dá valor mesmo! (...) Ontem eu fui tratado com seis comprimido de caramujo. Veio um sobrando, veio sete. Aí eu tirei um e abri. Despejei assim na mão, uma coisa amarelinha, igual gema de ovo. Aquilo chegou a cortar a sola da minha mão! Joguei no chão logo, e falei: Deus me livre! Você tá vendo o que vai no nosso estômago? É disso daí que 
parte a úlcera, a gastrite, parte tudo daí. Porque é que os lavrador tá cheio de úlcera aí, caído no hospitala? Através do caramujo! Porque vai tomando aqueles venenos, daí os problema vai amontoando. Por causa disso que a maioria morre. Porque hoje a doença tá pegando jovem e matando tudo."

\section{DISCUSSÃO}

\section{Considerações sobre Representação e Educação em Saúde}

O material de estudo evidenciou serem esporádicos os programas de educação em saúde na região, cujos discursos são assistidos passivamente pela população. Os enormes esforços de abstração e generalização exigidos para a compreensão destes discursos contribuem para o baixo aproveitamento de tais experiências educativas, que terminam por representar, para o grupo, uma espécie de "castigo a mais" após um dia extenuante de trabalho.

Mello et al. (1988), estudando a percepção popular das verminoses, concluíram que a população investigada demonstrava ser capaz de "repetir" as informações fornecidas pelo saber médico, sem, no entanto, integrá-las às suas práticas. Também nossos dados apontam para um nível elevado de "informações" sobre a esquistossomose. Não acreditamos, porém, na possibilidade de se tentar qualquer correlação direta entre o nível de "informações" sobre um problema e o comportamento frente a ele. No presente estudo, transpondo o nível da mera checagem das "repetições" de conhecimentos alheios, procuramos acompanhar o pensamento dos entrevistados de modo a trabalhar com a questão dos significados e da interpretação do grupo acerca de tais informações do saber médico, exaustivamente divulgadas na área. Com isso, verificamos que os conhecimentos ditos "corretos" não contêm necessariamente os elementos mínimos que lhes garantam qualquer consistência lógica, do ponto de vista do grupo em questão.

Esperar que o "nível de informações" forneça indícios sobre o comportamento adotado frente a um problema seria, em primeiro lugar, desconhecer este campo de mediação fundamental que é o campo das representações, onde efetivamente o pensamento humano interpreta e atribui sentido às novas informações e acomoda logicamente seus conteúdos. Além disso, mesmo as representações sociais, segundo Herzlich (1991), podem no máximo nos indicar alguns dos códigos a partir dos quais elaboram-se as significações ligadas às condutas coletivas, que, contudo, permanecem sempre múltiplas e complexas.

Pinto (1981) aponta para o fato de, no adulto, o conhecimento ser retido quando este possui para ele significado prático ou emocional, tendendo os adultos, em geral, a valorizar mais a compreensão dos fenômenos do que sua pura e simples retenção na memória. Segundo este autor, "para o adulto não é tão importante conhecer coisas novas isoladamente quanto sistematizar seu conhecimento, integrando os elementos novos em conjuntos mais harmônicos e totalizantes". O processo de aprendizagem do adulto seria definido, portanto, pela compreensão e explicação de sua própria vivência concreta, onde os novos conhecimentos são integrados na medida em que ampliem a compreensão, e não por seu valor intrínseco e abstrato.

Tal característica, comum aos adultos, potencializa-se quando em grupos imersos no mundo das coisas concretas e do trabalho produtivo, desenvolvendo uma forma de pensar muito concreta, com poucas manifestações abstratas. O material de estudo demonstrou que, entre os moradores da área investigada, as informações sobre a doença são depreendidas mais através da observação do comportamento dos guardas sanitários da Sucam do que através de palestras ou aulas, as quais em geral partem de proposições gerais e universais e utilizam-se de argumentações lógicas abstratas. São a observação da rotina de trabalho desenvolvida pelos guardas da Sucam e a experiência pessoal concreta com os diagnósticos por eles fornecidos para as "suas águas" e "suas fezes" que aparecem nos depoimentos, constituindo-se em "pistas epidemiológicas" que influem, em larga escala, na forma da população pensar e adquirir conhecimentos sobre a doença.

A busca dos guardas sanitários por moluscos nas águas resulta em fortes impressões junto à população, em face da seriedade e do empenho 
com que estes atores sociais embrenham-se em charcos, canais, alagados e margens de rios e lagoas à procura de pequenos caracóis, que são "pescados" em conchas metálicas. Este ritual exótico por si só já fornecia indícios suficientes para a associação entre a procura do caramujo nas águas e a doença no organismo humano. Entretanto, provavelmente no intuito de estreitar tal associação entre a doença e o molusco transmissor, os planejadores, técnicos de campanhas de controle e/ou médicos simplificaram de tal forma as informações que desejavam veicular, a ponto de divulgar a doença pelo nome de "caramujo", designação comum no estado do Espírito Santo, o que aponta fortemente para a construção de uma representação do molusco como sendo ele mesmo a "doença" que invade o organismo humano.

\section{Representações de Fatos Somáticos ligados à Doença e seu Tratamento}

Os depoimentos compilados na Tabela 3 têm por base a "aceitação" da idéia inicial de que o caramujo (esquistossomose) está dentro do corpo. Eles ilustram, a riqueza de imagens que se constroem e se consolidam, dando sentido aos conceitos e às informações dissociadas que a criatividade humana se encarrega de ordenar. Tais representações não são reflexos nem cópias de conceitos adquiridos passivamente; pelo contrário, elas trazem nitidamente a marca da imaginação individual e coletiva. Acompanhamos, em alguma extensão, o que se configura como uma dinâmica de apropriação do saber médico, através da seleção, teste de consistência e elaboração destes conteúdos, que passam a ser integrados a outros preexistentes.

TABELA 3. Freqüência das Possíveis Decorrências Graves da Doença do Caramujo apresentadas segundo as Partes do Corpo que podem ser Atingidas

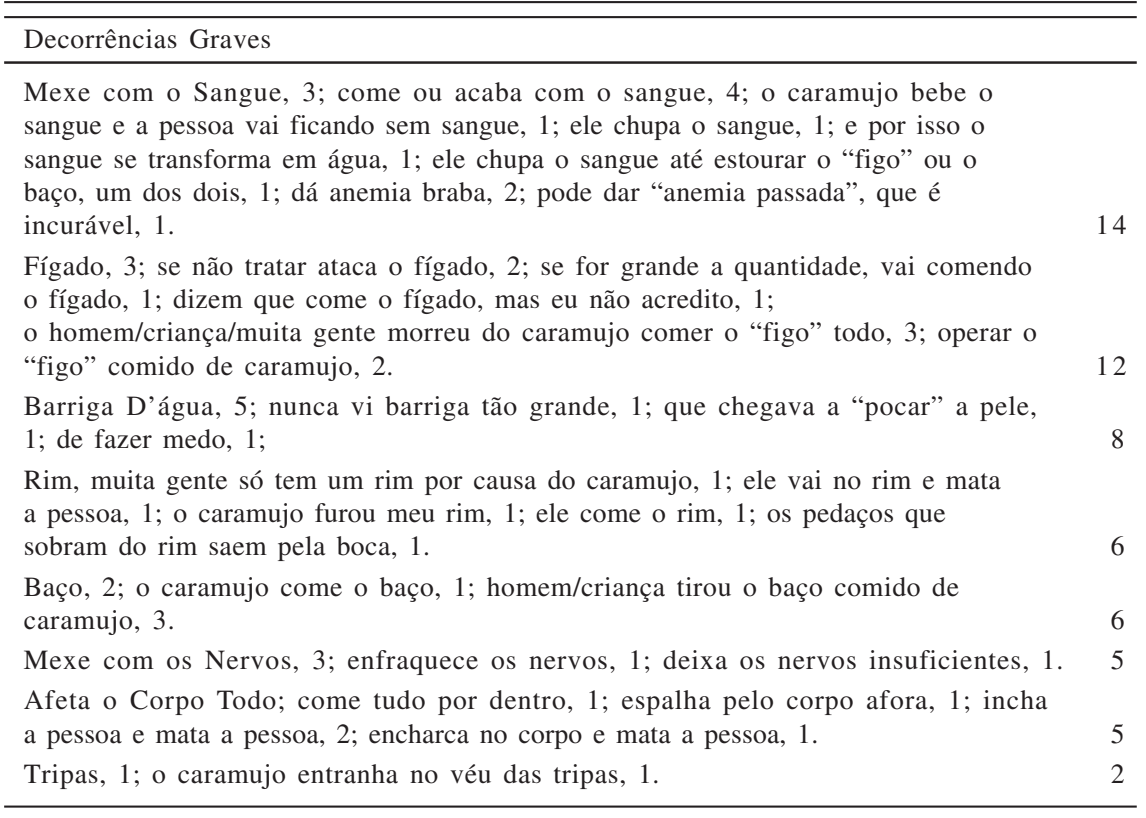

Obs.: Dados compilados a partir dos 36 depoimentos obtidos sobre o assunto.

A idéia inicial da existência do caramujo no interior do corpo deriva do saber médico e chega à população completamente desenraizada, desvinculada de outros conceitos científicos capazes de lhe conferir sentido no universo do saber médico onde foi gerada. Em algum mo- mento (para muitos um momento presente) tal idéia já foi estranha e surpreendente. Uma informação suficientemente distante do contexto imediato e da compreensão das pessoas, algo pertencente ao "mundo do discurso". Ao mesmo tempo, este dado novo era muito próximo, pois 
dizia respeito a eventos que ocorreriam dentro do corpo das pessoas, interpondo-se, portanto, entre as pessoas e o seu próprio sentir, seu sofrer. Segundo Moscovici (1961), é justamente neste espaço entre o "conceito" e a "percepção" que o ser humano constrói suas representações. A representação faz a passagem entre o conhecimento direto e o indireto, entre o testemunho e a observação. Os estilhaços de conhecimento, expressões ouvidas em algum lugar, retornam ao espírito, misturando-se às impressões vividas, até que as expressões comuns apossam-se deles. Ainda segundo Moscovici, "os conceitos sem percepções, as percepções sem conceitos, as palavras sem conteúdo e os conteúdos sem palavras buscam-se, deslocam-se e trocam-se (...) Para isso empregam-se as representações sociais, e é daí que elas resultam".

Parte-se de uma realidade presumida para depois sentir-se a necessidade de reconstruí-la, torná-la familiar. Assim, uma vez considerada a existência do caramujo no organismo, o mesmo é posto em ação pela atividade mental criativa. Ele é representado "andando" durante as cólicas abdominais, "comendo o sangue e os órgãos", "chupando os orgãos até que estourem", "criando família" ou "germinando". Tais atividades atribuídas ao caramujo migram do universo conhecido (atividades animais) para tornar o desconhecido familiar, o bizarro comum, integrando-o ao quadro coerente do real e usando uma linguagem que permita falar do "caramujo".

Contrariamente à fama de vilão que lhe é imputada, o caramujo não é um animal agressivo ou rápido, nem possui ganchos, pinças ou garras que favoreçam sua associação com ferimentos, mordidas ou com qualquer capacidade ofensiva evidente. Descrito como uma lesma inofensiva e, ao mesmo tempo, forçosamente associado pelo discurso médico a uma doença fatal, o caramujo instiga a curiosidade popular, alimentando uma contradição que se atenua através da sua mitificação. De acordo com o mito instituído, uma vez instalado no corpo humano, o caramujo teria uma ação lenta, sorrateira, porém progressiva. Esta idéia encontra ressonância na observação do molusco no meio ambiente. Ademais, sua concha, "onde ele se esconde", reforça esta sua capacidade mítica de dissimulação e de disfarce: "Ele é traiçoeiro... se esconde e gera. Pior que nós vivemos aqui no meio deles"; "O caramujo não parece, mas ele é um bicho atentado."

Vimos que este mito acerca de um molusco, tal como é visto no ambiente, habitar o organismo humano é fonte de descrédito e perplexidade. À medida que mais se aprofunda a discussão acerca da passagem do caramujo para o interior do corpo humano, com maior freqüência e vigor são postas em cheque as informações do saber médico divulgadas sobre o assunto. O mistério relacionado com a entrada do molusco no organismo levanta uma série de dúvidas quanto à existência efetiva da doença. A questão nos é então devolvida sob nova formulação: "por que motivo um molusco entenderia de entrar no organismo humano?

A hipótese da ingestão acidental do caramujo é a alternativa mais plausível encontrada pelo grupo, independente dos esforços da educação em saúde por substituí-la pela hipótese da penetração pela pele, confirmada pela ciência médica. A população sabe que esta segunda hipótese é a que o profissional de saúde quer ouvir, mas, por uma questão de coerência, entende que se um caramujo consegue passar através da pele, seguramente ele passa também pela boca. A idéia bizarra da ingestão acidental de um molusco é atenuada quando se aventa a possibilidade da existência de diminutas miniaturas do caracol, conhecidas como "vermes-caramujo", invisíveis e espalhados por toda a parte - solo, água, alimento, poeira -, podendo penetrar sorrateiramente no corpo humano sem serem percebidos e, uma vez dentro do corpo, transformando-se "naquilo".

A prolificidade e a abundância do molusco no meio ambiente confirmam, e a prova potencial infectante a ele atribuído, e a prova material de que o caramujo efetivamente entrou no corpo é fornecida pelo exame de fezes. Tal prova, porém, é vedada ao manuseio do homem comum, que não consegue encontrar em suas próprias fezes nem mesmo a "capinha" (concha) do caramujo. Apenas o profissional de saúde, detentor do conhecimento e do poder para tal, tem acesso às provas materiais do caramujo, em relação às quais o homem comum deverá mostrar aquiescência.

Uma vez mitificada a doença, somente uma solução também mitificada terá forças à altura 
para combatê-la. Esta solução é o "remédio de caramujo", "uma droga especial" reconhecida por unanimidade como a única capaz de "acabar com o caramujo". Desta maneira, é o medicamento especial que efetivamente materializa, para o homem comum, o poder mítico da medicina e da ciência, o único capaz de compreender, diagnosticar e neutralizar a ação do verme-caramujo. Mesmo que a droga mostre-se incapaz de "acabar com tudo" (vermes no organismo), ela. como vimos, promoveria uma espécie de desbaste periódico, fundamental para se evitar a metamorfose completa do caramujo em caracol no interior do corpo humano.

Em outros contextos, o uso de medicamentos pode ser representado como uma ação iminentemente curativa. Contudo, aqui ele adquire o status de ação preventiva por excelência, já que previne a transformação de uma doença simples e recorrente numa doença grave, envolta em representações de sofrimento e de morte bastante divulgadas na região.

Um exemplo extremo disto é encontrado nos depoimentos daqueles que, tendo experienciado as formas graves da doença no passado, pelo fato de continuarem a residir na área endêmica, já contraíram várias outras vezes o caramujo, ilustrando bem a forte valoração positiva do remédio como elemento de prevenção e de separação entre estas duas circunstâncias:

E.D. (extraiu o baço há 20 anos devido à esquistossomose) - "Todo ano eles fazem o exame duas, três vezes por ano. Inclusivamente por uns tempos não acusava o verme de jeito nenhum. Aí, tem poucos anos pra cá voltou a acusar o verme outra vez. Mas agora eu tomo remédio, né? Aí todo ano fica essa rotina, né? Faz o exame e se der o verme toma logo, que é prá não deixar formar aquela doença."

Assim, este grupo de moradores de uma área endêmica contrai periodicamente a doença ou convive permanentemente com este risco. Em tal situação, o problema deixa de ser o de "ter/não ter caramujo", posto que este é um evento comum na vida de todos. Este problema pode ter importância em outras áreas onde ainda possa ser visto como "um perigo a ser evitado", mas não pode ter o mesmo peso aqui. Assim, na área endêmica em estudo, a idéia de risco foi gradualmente sendo deslocada para uma outra condição: a de : estar/não estar tratado". A idéia de perigo passa a gravitar apenas em torno daqueles que "não fazem exames de fezes periódicos", "não tomam o remédio", "deixam o caramujo ir ficando". Estes, na representação desta população, configuram o grupo que se arrisca a ficar "realmente doente". Modificando o limiar do "perigo", do "risco", o grupo distancia um pouco mais o "pior" para melhor conviver com suas circunstâncias desfavoráveis.

Uma única entrevistada informou rejeitar a medicação. É possível que a expressão desta postura contra-hegemônica por parte de outros entrevistados tenha sido inibida pela situação de entrevista sob a qual trabalhamos. De maneira geral, no entanto, até a fração da população que se descreveu como assintomática expressou sua adesão ao uso do medicamento.

Lefèvre (1991) aponta os assintomáticos usuários de medicamentos como "pacientes exemplares", pois "combatem um inimigo que não se manifesta organicamente, ou seja, sem nenhum testemunho empírico que justifique este combate". Nestes casos, o indivíduo se aceita como doente "para o outro", isto é, para o médico, para a ciência, o que implica uma crença absoluta na verdade médica, na palavra da autoridade. Tal crença vigorosa foi de fato evidenciada em outro estudo realizado com a mesma população (Rozemberg, s/d).

No caso específico do "remédio de caramujo", vimos que $30 \%$ dos entrevistados descreveram experiências negativas, decorrentes não da doença, mas da utilização da droga, que foi inclusive apontada como responsável por doenças graves que levam os usuários à invalidez e à morte. Segundo Lefèvre (1991), tal situação indica uma grave fratura interna no "mito do medicamento", uma vez que a crença na ciência e em suas promessas defronta-se com a realidade amedrontadora dos fatos: o remédio demonstra sua insuficiência e seus efeitos colaterais.

$\mathrm{O}$ fato de a escolha entre duas situações consideradas igualmente desfavoráveis - a doença ou o remédio (e outras doenças a ele atribuídas) - pender para o lado do remédio indica, no caso específico da população investigada, não apenas a manutenção da crença na verdade médica curadora, mas muito particular- 
mente no "mito do caramujo" dela derivado. Ao continuar engolindo o remédio, o indivíduo está de alguma maneira "engolindo" esta história, improvável, misteriosa e cheia de incoerências.

\section{CONSIDERAÇÕES FINAIS}

Nosso estudo revelou um elevado nível de experiência pessoal e familiar com a esquistossomose. As ações oficiais ligadas ao diagnóstico, tratamento e monitoração da endemia são valorizadas, tendo sido fortemente introjetadas pela população. Apesar disso, no âmbito do Inquérito de Morbidade Referida, a esquistossomose (doença do caramujo) foi pouco mencionada, o que pode estar relacionado: 1. ao fato de a doença estar subsumida na categoria "verminoses", não estando a mesma especificada; 2. ao fato de a doença ser referida através de seus sintomas mais freqüentes; 3 . ao fato de $22,5 \%$ dos entrevistados terem se declarado assintomáticos; e 4. à maneira particular como a esquistossomose é representada enquanto problema de saúde.

Enquanto trabalhadores materiais diretos, os agricultores dependem, para sobreviver, de sua fina percepção acerca de eventos naturais que aprenderam a identificar e dominar com destreza. Não lhes é fácil simplesmente "aceitar" que aquilo que sentem ou sofrem no interior de seu corpo possa ter relação com o caramujo, uma espécie de animal que seria ao mesmo tempo uma doença. Assim, é possível que, ao lado de quadros efetivamente assintomáticos, existam outros onde possíveis sintomas vivenciados não sejam atribuídos ao caramujo, o que demonstra que parte da população permanece refratária à "crença" em tal doença.

Além disso, vimos que o conjunto das práticas e representações em torno deste problema coloca-o numa posição inatingível pelas práticas e receitas caseiras capazes de curar as demais verminoses. Assim apesar de ser um problema falado, vivido, medicado e conhecido no dia a dia dessas comunidades, a doença do caramujo representa um problema em grande parte "alheio", já que ela é ao mesmo tempo "trazida" e "solucionada" pela Sucam, não chegando a população a tomar posse da mesma e a problematizá-la como objetivo de suas próprias ações de saúde. Uma vez detectada, a doença do caramujo já vem com a sua solução pronta, garantida, gratuita e de origem exógena: " $A$ gente não liga por causa do caramujo, porque vem a Sucam e dá o remédio. Aí a gente volta e fala: Ah! Vamos trabalhar lá mesmo (várzea de arroz contaminada). A Sucam passa de novo e dá o remédio."

É evidente que não se trata aqui de uma "opção" por se expor à contaminação numa área insalubre. Inúmeras dificuldades concretas determinam a contingência de se depender de tais condições para o trabalho de subsistência. O que se discute aqui é a relação de dependência que se estabelece entre a população e as "soluções" (no caso, os recursos terapêuticos) disponíveis para a doença do caramujo. Assim, ao exigir, questionar e criticar o trabalho realizado pela Sucam, assumindo, em alguma medida, a monitoração do problema nos níveis familiar e comunitário, a população demonstra seu esforço em se apropriar desta questão.

Os temas trabalhados neste artigo correspondem à primeira hora de duração das entrevistas dos sujeitos desta pesquisa. Apesar de serem todas questões abertas, podendo dar margem a referências sobre a contaminação do meio pelas fezes e sobre as ações de saneamento ambiental, tema central para qualquer discussão sobre a esquistossomose, tais aspectos foram mencionados por apenas 7,5\% dos entrevistados. Um próximo artigo tratará destas referências, bem como das demais questões da entrevista que versam principalmente sobre o ciclo de transmissão e sobre a prevenção da endemia. Propositalmente, no presente trabalho sequer mencionamos estes aspectos tão fundamentais para a prevenção e controle da esquistossomose, jjá que sua ausência ilustra muito bem os efeitos atuais do "mito do caramujo" sobre as representações da esquistossomose. A mitificação da doença, que em parte decorre da polarização excessiva da atenção das autoridades na prevenção do contato humano com as águas (onde efetivamente o homem se infecta) e na obtenção de um alto nível de adesão ao uso do medicamento, atua como um fetiche sobre a população, concentrando-a no medo do molusco e na adoção do quimioterápico.

Com isso, porém, desvia-se sistematicamente a atenção popular das questões que efetiva- 
mente recolocariam a discussão no âmbito das ações humanas concretas, ligadas ao saneamento básico e às condições gerais de vida que concorrem para a manutenção da transmissão da esquistossomose.

Assim, apesar de conduzir a adesão popular aos procedimentos preventivos imediatos, a representação da esquistossomose aqui esboçada reflete a ausência de uma discussão mais madura e conseqüente entre técnicos e população, bem como a insistência em se manter a população numa posição de inferioridade frente ao saber médico, postura que ainda hoje caracteriza as ações de saúde pública em nossas sociedades.

\section{AGRADECIMENTOS}

À Dra Maria Cecília de Souza Minayo por sua orientação e leitura crítica do original. Aos Drs. Carlos Coimbra Jr. e Odécio Sanches pelas consultorias fundamentais à pesquisa de campo. Ao Dr. Frederico S. Barbosa e sua equipe do Programa de Controle da Esquistossomose da Ensp/Fiocruz, à Fundação Nacional de Saúde e à Prefeitura Municipal de Conceição do Castelo pelo apoio ao desenvolvimento do trabalho de campo.

\section{RESUMO}

ROZEMBERG, B. Representação Social de Eventos Somáticos Ligados à Esquistossomose. Cad. Saúde Públ., Rio de Janeiro, 10(1): 30-46, jan/mar, 1994.

Esta pesquisa objetiva analisar criticamente as representações sociais da esquistossomose numa área rural endêmica do estado do Espírito Santo. Os resultados da pesquisa foram desmembrados em três artigos, a fim de permitir um maior detalhamento da descrição e a explicação das inter-relações e condicionamento sobre o modo como os indivíduos atribuem sentido à esquistossomose. Neste artigo são apresentados apenas as representações da esquistossomose enquanto processo orgânico, incluindo os tópicos sintomatologia, tratamento e etiologia.
Transpondo o nível da mera checagem de conhecimentos sobre a doença, verificamos que estes últimos, apesar de poderem ser "repetidos" pela população, não contêm necessariamente os elementos mínimos que lhes garantam qualquer consistência lógica, do ponto de vista do grupo em questão. A prática dos programas de controle desenvolvidos pela Fundação Nacional de Saúde demonstrou ter grande influência sobre a forma de se pensar o problema da esquistossomose na área investigada.

Destaca-se, no imaginário local, a mitificação do molusco transmissor da esquistossomose como sendo capaz de alojar-se no organismo humano, devorando-o inteiramente.

Discute-se a baixa credibilidade na existência de tal doença e o papel do quimioterápico no contexto estudado. As percepções mitificadas da esquistossomose desviam a atenção popular das questões de saneamento e condições gerais de vida ligadas à endemia. Palavras-Chave: Representação Social; Esquistossomose; Educação em Saúde

\section{REFERÊNCIAS BIBLIOGRÁFICAS}

HERZLICH, C., 1991. A Problemática da representação social e sua utilidade no campo da doença. Physis Revista de Saúde Coletiva, 1: 23-35.

LEFEVRE, F., 1991. O Medicamento como Mercadoria Simbólica. São Paulo: Cortez.

MELLO, D.A.; PRIPAS, S.; FUCCI, M.; SANTORO, M.C. \& PEDRAZZANI, E.S., 1988. Helmintoses intestinais. 1. Conhecimentos, atitudes e percepção da população. Revista de Saúde Pública, 22: 140-149.

MINAYO, M. C. S., 1992. Quantitativo e Qualitativo em Indicadores de Saúde: Revendo conceitos. Trabalho apresentado na Mesa Redonda: Indicadores de Saúde. II Congresso de Epidemiologia, Belo Horizonte, 1992 (Mimeo.)

MOSCOVICI, S., 1978. Representação Social da Psicanálise. Rio de Janeiro: Zahar.

PINTO, J. B., 1981. A educação de adultos e o desenvolvimento rural. In: Educação Rural no Terceiro Mundo (J. Werthein \& J. D. Bordenave, orgs.), Rio de Janeiro: Paz e Terra.

ROZEMBERG, B., s/d. O consumo de calmantes e o problema de nervos entre lavradores. Revista de Saúde Pública. (no prelo). 